\title{
Reducing Rates of Molten Iron Oxide by Solid Carbon or Carbon in Molten Iron*
}

\author{
By Akira SATO,** Goro ARAGANE,** Kazushige KAMIHIR $A^{* * *}$ and \\ Shiro YOSHIMATSU ***
}

\section{Synopsis}

In order to collect basic data on the smelting reduction process which consists of blowing powder iron ore and powder coal into molten iron bath with oxygen gas for a partial combustion, the reduction rates of molten iron oxide by the solid carbon or the carbon in molten iron were measured. Molten iron oxide in a steel or an alumina crucible was reduced by a rotating carbon rod. The carbon in molten iron in an alumina crucible was reacted with molten iron oxide which was melted in a steel container beforehand. The reduction rates were calculated from the amount of $\mathrm{CO}$ gas evolved. The following results were obtained:

(1) The reduction rates of molten iron oxide by the solid carbon were $0.21 \sim 0.82 \times 10^{-4} \mathrm{~mol}-\mathrm{FeO} / \mathrm{cm}^{2} \cdot s$ at $1420 \sim 1620^{\circ} \mathrm{C}$, and the activation energy of the reaction were 75 and $31 \mathrm{kcal} / \mathrm{mol}$ for a steel and an alumina crucibles, respectively.

(2) The reduction rates of molten iron oxide by the carbon in molten iron were $1.1 \sim 3.3 \times 10^{-4} \mathrm{~mol}-\mathrm{FeO} / \mathrm{cm}^{2}$.s at $1420 \sim 1620^{\circ} \mathrm{C}$, and the activation energy of the reaction was $44 \mathrm{kcal} / \mathrm{mol}$.

(3) It was concluded that the reaction rate between the solid iron oxide and the carbon in molten iron was the highest among reactions between the solid or the molten iron oxide and the solid carbon, the carbon in molten iron, $\mathrm{CO}$, or $\mathrm{H}_{2}$ gas based on the results so far.

Key words: ironmaking; smelting reduction; direct reduction; reduction; reduction rate; iron ore; coal.

\section{Introduction}

The productivity of a smelting reduction furnace per unit volume should be high to be economically feasible compared with those of a blast furnace and a shaft furnace. ${ }^{1)}$ A blast furnace and a shaft furnace belong to reactors with packed layers, and have high efficiencies with respect to the heat transfer and the reaction. In order to obtain a high productivity in a smelting reduction furnace, the reaction area between oxide and reductant can be increased by blowing powder iron ore and powder coal into molten iron bath with oxygen gas for a partial combustion. In smelting reduction of iron ore, both the feeding of heat of large quantity and the protection of refractories from erosion of slags containing molten iron oxide are the most important subjects to be solved, and many processes are proposed to solve those subjects. ${ }^{2)}$

Table 1 shows elementary processes into reactants of iron ore and coal blown into molten iron bath with oxygen gas for a partial combustion, elementary reactions between reactants, and the evaluation by the authors on quantity of data published up to the present for them. The elementary processes of iron ore containing iron oxide $\left(\mathrm{Fe}_{2} \mathrm{O}_{3}\right)$, gangue and phosphides into reactants (outside of each row) are consisted of, in detail, dissociation of $\mathrm{Fe}_{2} \mathrm{O}_{3}$ into $\mathrm{Fe}_{3} \mathrm{O}_{4}$, dissociation of $\mathrm{Fe}_{3} \mathrm{O}_{4}$ into $\mathrm{FeO}$, melting of $\mathrm{FeO}$ and dissolution of $\mathrm{FeO}$ into molten slag. The elementary processes of coal containing fixed carbon, volatile matter, ash and sulphides into reactants (outside of each column) are consisted of, in detail, followings: Decomposition of volatile matter and gasification of fixed carbon and volatile matter by partial combustion into $\mathrm{H}_{2}$ and $\mathrm{CO}$ gases. Evaporation of volatile matter and gasification of fixed carbon into hydrocarbon gases $\left(\mathrm{C}_{m} \mathrm{H}_{n}\right)$. Garbonization of coal into cokes (solid carbon). Dissolution of carbon in fixed carbon and volatile matter into molten iron and molten slag. The elementary reactions between reactants are reductions of 5 kinds of iron oxides by 6 kinds of reductants. In development of a smelting reduction process of iron ore with coal, data on all of these elementary processes and reactions are desired very much. Moreover, when a pre-reduced iron ore instead of iron ore is blown into molten iron bath, melting rates of reduced iron pellet is also very important. Therefore, authors have carried out a series of researches. ${ }^{3-13)}$ The elementary processes and reactions marked with $\odot$ were those evaluated to be lacking data and studied by authors, and those marked with $\bullet$ are reactions for the present report.

The results obtained in the series of researches so

Table 1. Elementary processes into reactants of iron ore and coal blown into iron bath, elementary reactions between reactants, and the evaluation on the quantity of data for them.

\begin{tabular}{|c|c|c|c|c|c|c|c|}
\hline \multirow{2}{*}{\multicolumn{3}{|c|}{$\begin{array}{l}\text { Molten iron bath } \\
\text { at } 1300 \sim 1600^{\circ} \mathrm{C}\end{array}$}} & \multicolumn{5}{|c|}{$\begin{array}{ll}\langle\text { Iron ore }> & \text { 2. Gangue } \\
& \text { 3. P }\end{array}$} \\
\hline & & & \multirow{2}{*}{\begin{tabular}{|c|}
- \\
$\left\langle\mathrm{Fe}_{2} \mathrm{O}_{3}\right\rangle$ \\
\end{tabular}} & \multirow{2}{*}{$\begin{array}{|cc|}x & \odot \\
\left\langle\mathrm{Fe}_{3} \mathrm{O}_{4}\right\rangle \\
\end{array}$} & \multirow{2}{*}{\begin{tabular}{|l|}
$x \odot \odot$ \\
$\langle\mathrm{FeO} O\rangle$ \\
\end{tabular}} & \multirow{2}{*}{$\frac{x \odot}{\{\mathrm{FeO}\}}$} & \multirow{2}{*}{\begin{tabular}{|c|}
$x$ \\
$\{\mathrm{FeO}\} \mathrm{s}$ \\
\end{tabular}} \\
\hline \multirow{7}{*}{$\begin{array}{l}\text { <Coal> } \\
\text { 1. Fixed C } \\
\text { 2. Volatile } \\
\text { matter } \\
\text { 3. Ash } \\
\text { 4. S }\end{array}$} & & & & & & & \\
\hline & $\Delta$ & $\left(\mathrm{H}_{2}\right)$ & 0 & 0 & 0 & $\Delta$ & $\Delta$ \\
\hline & $\Delta$ & $(\mathrm{CO})$ & 0 & 0 & 0 & $\Delta$ & $\Delta$ \\
\hline & $x$ & $(\mathrm{CmHn})$ & $\Delta$ & $\Delta$ & $\Delta$ & $x$ & $x$ \\
\hline & $x$ & $\langle C\rangle$ & 0 & 0 & 0 & $\Delta 0$ & $\Delta \odot$ \\
\hline & $\Delta$ ○ & $\{\mathrm{C}\} \mathrm{m}$ & $\Delta \odot$ & $\Delta \odot$ & $\Delta \odot$ & $\times 0$ & $x \odot$ \\
\hline & $x$ & $\{C\}_{\mathbf{s}}$ & $x$ & $x$ & $x$ & $x$ & $x$ \\
\hline
\end{tabular}

State: 〈 > Solid, \{ \} Liquid or dissolved, ( ) Gas m: Metal, s: Slag

Data: O Plenty, $\triangle$ Several, $\times$ None, $\odot$ With a series of the research, - Present work

* Originally published in Tetsu-to-Hagané, 73 (1987), 812, in Japanese. English version received on May 12, 1987; accepted in the final form on July 3,1987 . (C) 1987 ISIJ

** Metal Processing Division, National Research Institute for Metals, Nakameguro, Meguro-ku, Tokyo 153.

*** Process Metallurgy Division, National Research Institute for Metals, Nakameguro, Meguro-ku, Tokyo 153. 
far are as follows: The melting rate of a reduced iron pellet into molten iron was studied by eye or measuring the amount of $\mathrm{CO}$ gas evolution when a pellet was dropped onto the surface of molten iron. ${ }^{3,4)}$ The effect of iron oxide content, gangue content and composition, carbon and temperature of molten iron on the melting rate was examined. An iron oxide pellet or a lump of iron ore was immersed into a molten $\mathrm{Fe}-\mathrm{C}$ or $\mathrm{Cu}-5 \% \mathrm{Fe}$ alloy, and its structure and the oxygen concentration were investigated. ${ }^{12)} \quad \mathrm{Fe}_{2} \mathrm{O}_{3}$ was dissociated by the heat of molten metal into $\mathrm{Fe}_{3} \mathrm{O}_{4}$ and $\mathrm{FeO}$, and $\mathrm{FeO}$ in a solid or a liquid state was reduced by the carbon in molten iron. Granular coal was added onto the surface of molten $\mathrm{Fe}-\mathrm{C}$ alloy to carburize molten iron bath. ${ }^{10,13)}$ The carburization rate increased with increasing fixed carbon content and decreasing ash content of coal. Iron oxide pellet of $\mathrm{Fe}_{2} \mathrm{O}_{3}$. $\quad \mathrm{Fe}_{3} \mathrm{O}_{4}$ or $\mathrm{FeO}$ was dropped onto the surface of molten $\mathrm{Fe}-\mathrm{C}$ alloy, and the reduction rates were investigated by measuring the amount of $\mathrm{CO}$ gas evolution. ${ }^{7)}$ Mixture consisted of master slag and $\mathrm{FeO}$ was added onto the surface of molten iron or molten copper in a graphite crucible to measure the amount of $\mathrm{CO}$ gas evolution. ${ }^{8)}$ The reduction rate of $\mathrm{FeO}$ in molten slag by the carbon in molten iron and graphite was obtained.

The subjects to be studied in future are as follows from Table 1: The melting rate of iron oxide into molten slag is important for iron ore containing much gangue content. The effect of phosphorus on the reduction rate is also significant for iron ore containing much phosphide content. There is no report on the carbonization of coal by molten iron. The dissolution of carbon into molten slag is very slight up to the present, ${ }^{14)}$ but might be increased as much as having effect on the reduction rate of iron oxides. The sulphur content in molten iron or molten slag might have effect on the reduction rate of iron oxides.

\section{Researches up to the Present and a Plan of the Present Study}

In the case of the reduction of molten iron oxide by the solid carbon, the reaction mode changes with the concentration of $\mathrm{FeO}$, and the solution-loss reaction determines the overall reaction rate above $50 \%$ FeO. ${ }^{15}$ In most of experiments up to the present, the reduction rate was calculated from the composition and the volume of the gas evolved after dropping a piece of iron oxide into a hot carbon crucible. ${ }^{16-20)}$ In these experiments, the product iron melt might give some effects on the reaction rate. That is, the carbon dissolved in the product iron melt might react with the molten iron oxide. In the experiment using a rotating carbon rod, where the carbon dissolved in the product iron melt might have no effect on the reduction rate, the reduction rate was obtained from the concentration of slag, and therefore, pure molten iron oxide could not be used. ${ }^{21}$ Accordingly, in the present experiment the reduction rate is obtained from the amount of $\mathrm{CO}$ gas evolution using a rotating carbon rod in pure $\mathrm{FeO}$ melt. The rotation speed of the carbon rod is as low as possible, but prevents the product iron melt from adhering on the rod. An iron crucible is the best for a container of molten iron oxide, but it can not be used above $1500^{\circ} \mathrm{C}$ because of its melting point of $1539^{\circ} \mathrm{C}$. Experiments above $1500^{\circ} \mathrm{C}$ are carried out with recrystallized alumina crucibles because their erosion by molten iron oxide are small.

In the case of the reduction of molten iron oxide by the carbon in molten iron, most experiments up to the present were carried out by dropping a piece of solid iron oxide onto the molten iron bath containing carbon $^{7,20,22-24)}$ The carbon in molten iron might react with solid iron oxide or partially liquified iron oxide. Lloyd et al. ${ }^{24)}$ melted a small amount of iron oxide in an iron container and then put the container onto the iron bath containing carbon. They reported that the reduction rate of molten iron oxide by the carbon in molten iron was lower by $10 \%$ than that of solid iron oxide. Accordingly, in the present experiment iron oxide is melted in steel container beforehand, and then the bottom of the container is melted away by the iron bath containing carbon. The amount of molten iron oxide to be used must be enough to cover the surface of molten iron, and therefore, the reaction area is the same as that of the surface of molten iron.

\section{Experimental}

Figure 1 shows a schematic diagram of the experimental apparatus with a Tammann furnace for controlled atmosphere melting. The temperature was kept at a desired one within $\pm 5^{\circ} \mathrm{C}$. The amount of $\mathrm{CO}$ gas evolved was measured with an integrating gas meter after the gas was cooled and cleaned. Because the measurable range of this meter was 5 to $300 \mathrm{l} / \mathrm{h}$, nitrogen gas was flowed at the rate of $60 \mathrm{l} / \mathrm{h}$.

Figure 2 shows a schematic diagram of experiment for reduction of molten iron oxide by the solid car-

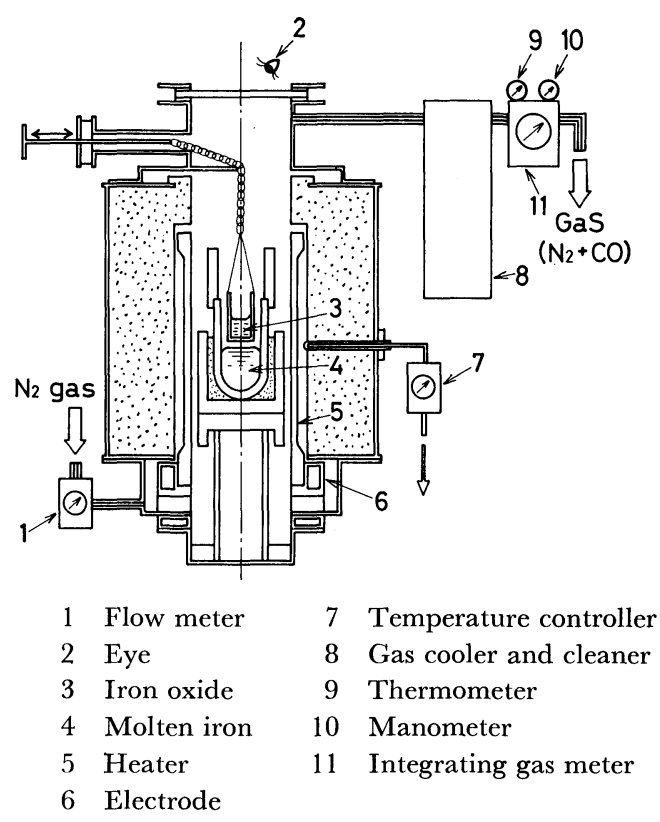

Fig. 1. Schematic diagram of experimental apparatus with a Tammann furnace for controlled atmosphere melting. 


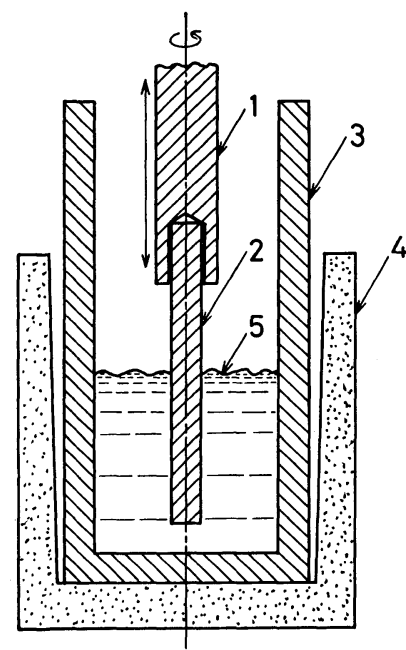

1 Graphite rod 15\%

2 Graphite rod 3 10\%

3 Iron or alumina crucible $50 \mathrm{~mm}$ ID

4 Alumina crucible

$5 \mathrm{FeO}$ melt

Fig. 2. Schematic diagram of experiment for reduction of molten iron oxide by solid carbon.

bon. Molten iron oxide was contained in a steel or an alumina crucible (ID $50 \mathrm{~mm}$, Depth $190 \mathrm{~mm}$ ), and its depth was about $100 \mathrm{~mm}$. Reagent $\mathrm{FeO}$ (93.8 \% $\mathrm{FeO}$, reduced by $\mathrm{H}_{2}$ gas from JIS 1st grade reagent $\mathrm{Fe}_{2} \mathrm{O}_{3}$ ) was used. The purity, the diameter and the rotation speed of carbon rod were five-nine, $3 \sim 10 \mathrm{~mm}$, and 0,6 and $60 \mathrm{rpm}$, respectively. The experimental procedure was as follows: The molten iron oxide at a predetermined temperature in a nitrogen atmosphere was stirred with a iron rod. The carbon rod was lowered at about $10 \mathrm{~mm}$ above the surface of molten iron oxide and heated for $3 \mathrm{~min}$. Then, the gas flow rate was measured for $2 \mathrm{~min}$. The carbon rod was immersed into the molten iron oxide and the gas flow rate was measured every $5 \mathrm{~s}$ for 3 min. The carbon rod pulled out from molten iron oxide was quenched by nitrogen gas, and its diameter and its depth were measured. The reproducibility was confirmed by comparing the results of repeated runs in each experimental condition.

Figure 3 shows a schematic diagram of experiment for reduction of molten iron oxide by the carbon in molten iron. Fe- $\mathrm{G}$ alloy of $1.5 \mathrm{~kg}$ made from an electrolytic iron and an electrode graphite was kept in a recrystallized alumina crucible. In some experiments graphite blocks were adhered at the bottom of crucibles to keep the carbon concentration constant. A graphite cylinder at the top of the crucible was aimed at the protection of apparatus from splashing and the conversion of $\mathrm{CO}_{2}$ gas into $\mathrm{CO}$ gas. The container to melt iron oxide beforehand was made of steel (ID $28 \mathrm{~mm}$, Depth $90 \mathrm{~mm}$ ), and the iron oxide of $50 \mathrm{~g}$ was used mainly. The experimental procedure was as follows: The molten iron at a predetermined temperature in a nitrogen atmosphere was stirred and its surface was cleaned, and a sample for chemical analysis was sucked out with a silica tube.

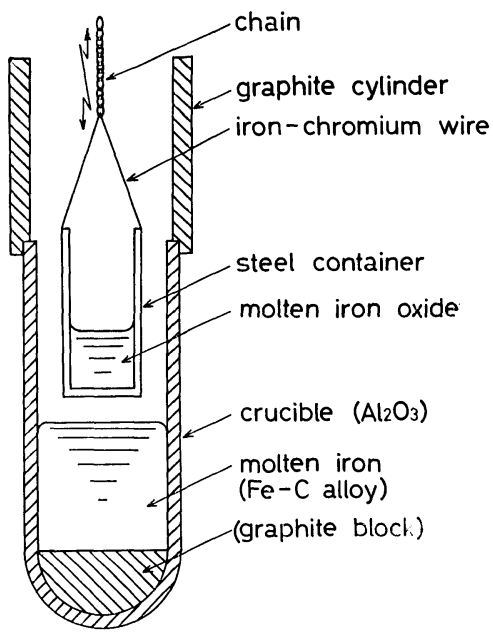

Fig. 3. Schematic diagram of experiment for reduction of molten iron oxide by carbon in molten iron.

The steel container was lowered at about $10 \mathrm{~mm}$ above the surface of molten iron. The gas flow rate was measured during melting of iron oxide. The time for melting of iron oxide were $8 \sim 15 \mathrm{~min}$ depending on the experimental temperature and the amount of iron oxide. The melting of iron oxide was confirmed by eye through a viewing window. The steel container was lowered and its bottom was melted by the molten iron. The gas flow rate was measured every $5 \mathrm{~s}$ for $3 \mathrm{~min}$. The reproducibility was confirmed with repeated runs.

\section{Results}

In reduction of molten iron oxide by the solid carbon or the carbon in molten iron, an overall reaction can be expressed by Eq. (1), though reactions expressed by Eqs. (2) and (3) are simultaneous ones.

$$
\begin{aligned}
& \mathrm{FeO}(l)+\mathrm{G}(s \text { or } d)=\mathrm{Fe}(s \text { or } l)+\mathrm{CO}(g) \\
& \mathrm{FeO}(l)+\mathrm{CO}(g)=\mathrm{Fe}(s \text { or } l) \\
& \mathrm{CO}_{2}(g)+\mathrm{C}(s \text { or } d)=2 \mathrm{CO}(g)
\end{aligned}
$$

where, $d, g, l, s$ in ( ): dissolution, gas, liquid and solid, respectively.

Tsukihashi et al. ${ }^{20)}$ reported that $\mathrm{CO}_{2} /\left(\mathrm{CO}+\mathrm{CO}_{2}\right)$ was 0.17 when iron oxide reacted with only bottom graphite of crucible whose side wall was covered with an alumina tube, while the value was 0.055 when the side wall was not covered. From this result it can be confirmed that the reaction expressed by Eq. (3) takes place in the reduction of molten iron oxide by the solid carbon or the carbon in iron melt. However, the overall reaction rate is the most important, and then, the reaction rate was obtained with Eq. (1). Even without a hot graphite cylinder above the crucible, $\mathrm{CO}_{2} /\left(\mathrm{CO}+\mathrm{CO}_{2}\right)$ was less than $0.01,{ }^{4)}$ and therefore, the $\mathrm{CO}_{2}$ gas concentration can be neglected in the present experiment with a hot graphite cylinder. The reaction rate was calculated with the $\mathrm{CO}$ gas evolution rate. In this report, the reaction rate (mol$\left.\mathrm{FeO} / \mathrm{cm}^{2} \cdot \mathrm{s}\right)$ converted from the apparent reaction con- 
stant is used for the comparison with the results of other authors.

\section{Reduction Rate of Molten Iron Oxide by Solid Carbon}

Figure 4 shows the amount of $\mathrm{CO}$ gas evolution with the time during the reduction of molten iron oxide by the solid carbon at various temperatures. Carbon rods of $5 \mathrm{~mm}$ in diameter were immersed 40 $\mathrm{mm}$ in depth into molten iron oxide in an alumina crucible, and were not rotated. The amount of $\mathrm{CO}$ gas evolution is little up to $40 \mathrm{~s}$, but it increased linearly with the time after $50 \mathrm{~s}$. The CO gas evolution rates were obtained from the slope of these lines. The area of reaction interface was calculated from the diameter and the immersion depth of the carbon rod measured after the experiment. A roundish end and a slight groove at the meniscus were usually observed at the carbon rod after the experiment. Moreover, the surface of the carbon rod after the experiment was softer than that before the experiment. The area of the bottom end and the groove curve was neglected in calculating the area of reaction interface. The reason why the area of bottom end can be neglected is described in discussion.

\section{Immersion Depth of the Carbon Rod in Molten Iron} Oxide

Figure 5 shows the reduction rate of molten iron oxide in steel crucibles at 1420 and $1470^{\circ} \mathrm{C}$ and the immersion depth of the carbon rod with different rotation speeds. The reduction rate increases below $20 \mathrm{~mm}$ of the immersion depth, and becomes nearly constant above $20 \mathrm{~mm}$. The reduction rate increases with temperature, but the rotation speed of carbon rod has little effect on the reduction rate. The immersion depth of carbon rod about $40 \mathrm{~mm}$ was used in the following experiments.

\section{Reduction Temperature}

Figure 6 shows the reduction rate of molten iron oxide in steel and alumina crucibles at various temperatures. The reduction rates obtained are between two straight lines. In detail, however, the reduction rates with steel crucibles at $1390^{\circ} \mathrm{C}$ are higher than those at $1420^{\circ} \mathrm{C}$, and the reduction rates at $1420^{\circ} \mathrm{C}$ with alumina crucibles are higher than those with

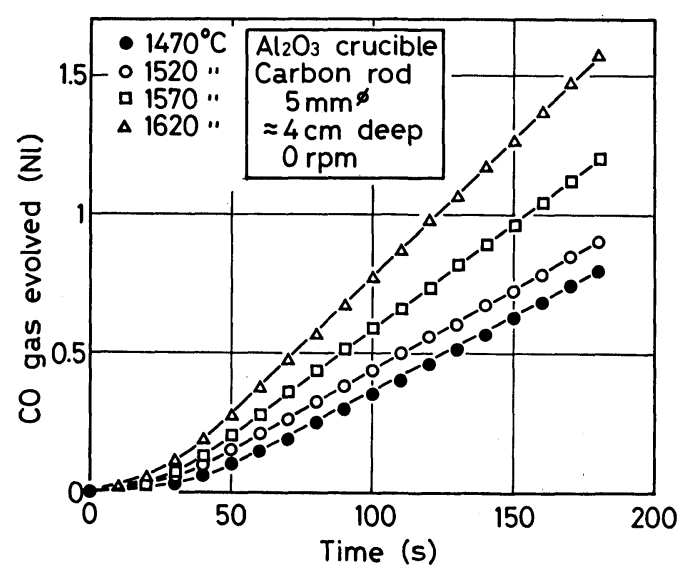

Fig. 4. Amount of $\mathrm{CO}$ gas evolution and the time during the reduction by the solid carbon. steel ones. The carbon rods used at $1390^{\circ} \mathrm{C}$ with steel crucibles and at $1420^{\circ} \mathrm{C}$ with alumina crucibles were observed to have reacted locally and several hollows were formed on them.

\section{Effect of $\mathrm{Al}_{2} \mathrm{O}_{3}$ in Molten Iron Oxide on the Reduction Rate}

Because steel crucibles could not be used above $1500^{\circ} \mathrm{C}$, alumina ones were used. The concentration of $\mathrm{Al}_{2} \mathrm{O}_{3}$ in molten iron oxide after 12 reduction runs were 4,11 , and $18 \%$ at experimental temperatures of 1420,1520 and $1620^{\circ} \mathrm{C}$, respectively. Therefore, the effect of $\mathrm{Al}_{2} \mathrm{O}_{3}$ in molten iron oxide on the reduction rate was examined. $\mathrm{FeO}$ powder and $\mathrm{Al}_{2} \mathrm{O}_{3}$ (1st grade reagent) powder were mixed and melted in steel crucible, and then, the reduction rate was measured as the same procedure mentioned above. Figure 7 shows the effect of $\mathrm{Al}_{2} \mathrm{O}_{3}$ concentration on the reduction rate of molten iron oxide at different rotation speeds. The reduction rate increases up to about $2.5 \%$, shows the maximum here and then decreases with increasing the $\mathrm{Al}_{2} \mathrm{O}_{3}$ content above $2.5 \%$.

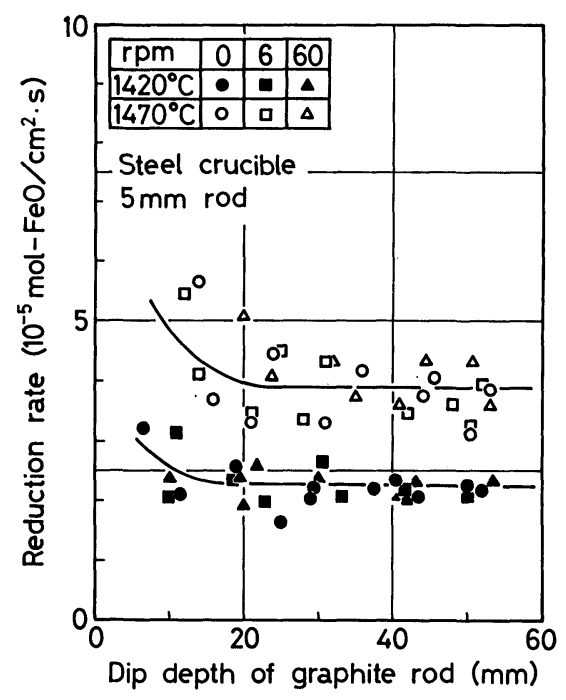

Fig. 5. Reduction rates and the dip depth of carbon rod.

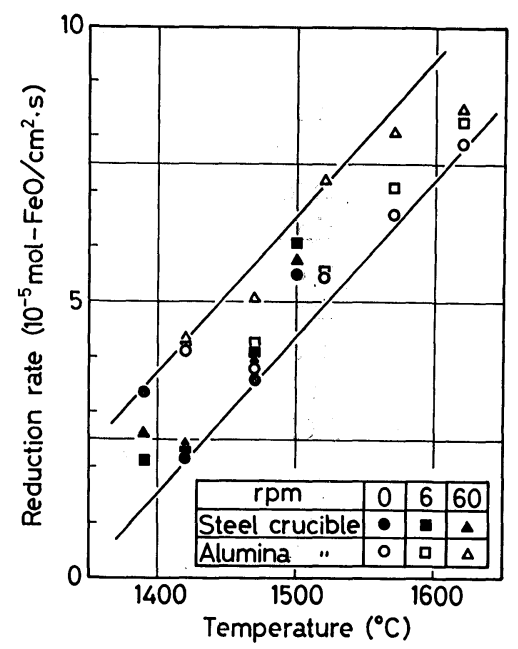

Fig. 6. Reduction rates by the solid carbon and the temperature. 


\section{Diameter of Garbon Rod}

Figure 8 shows the reduction rate of molten iron oxide in alumina crucibles and the diameter of carbon rod. The reduction rate shows the maximum at 5 $\mathrm{mm}$ in diameter. The reduction rates increase with increasing the rotation speed of carbon rod. When the rod was rotated at $60 \mathrm{rpm}$, the surface of molten iron oxide in crucible formed concavity, and therefore, the immersion depth of carbon rod decreased.

\section{Reduction Rate of Molten Iron Oxide by Carbon in Molten Iron}

Figure 9 shows the amount of $\mathrm{CO}$ gas evolution with the time during the reduction by the carbon in molten iron containing carbon above $4 \%$. When the density of FeO melt is $3.5 \sim 4.5 \mathrm{~g} / \mathrm{cm}^{3}$, the depth of molten iron oxide of $50 \mathrm{~g}$ is $6 \sim 7 \mathrm{~mm}$. Therefore, the surface of molten iron must be covered with molten iron oxide. The amount of $\mathrm{CO}$ gas is calculated to be $15.6 l$ when $\mathrm{FeO}$ of $50 \mathrm{~g}$ is reduced. The reduction rate is considered to be low at the beginning and also the ending of reaction, because the agitation by $\mathrm{CO}$ gas is low at the beginning and because the amount of $\mathrm{FeO}$ is not enough to cover the surface of molten iron at the ending. Therefore, the curves shown in Fig. 9 should be $S$ curves, as seen obviously

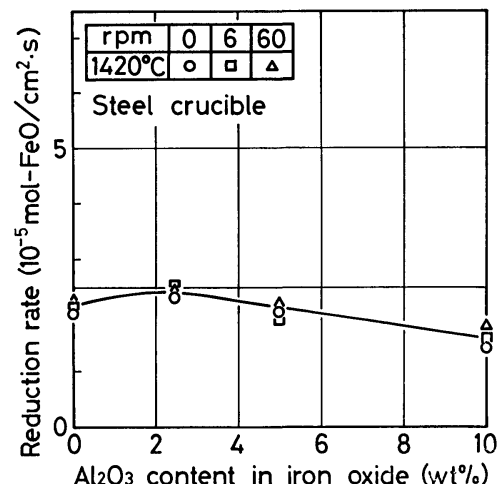

Fig. 7. Reduction rates by the solid carbon and the $\mathrm{Al}_{2} \mathrm{O}_{3}$ content in molten iron oxide.

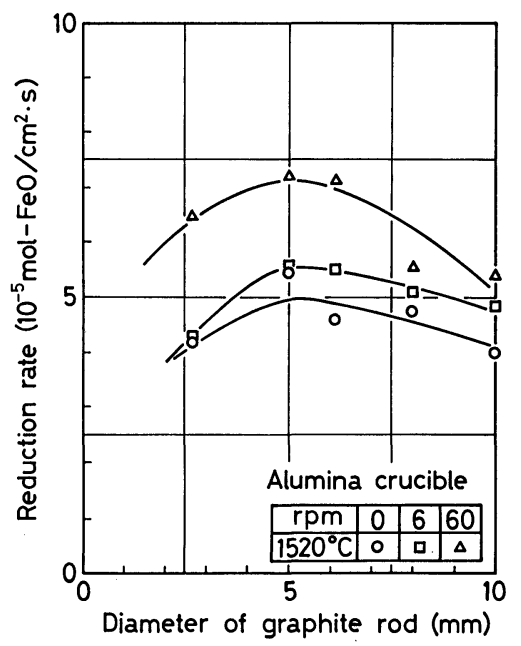

Fig. 8. Reduction rates by the solid carbon and the diameter of carbon rod. from the curve of $1620^{\circ} \mathrm{C}$. The reduction rate was calculated when the amount of $\mathrm{GO}$ gas evolution increased linearly with the time, because the area of the reaction interface could be the same as that of the surface of molten iron bath.

\section{Carbon Concentration in Molten Iron}

Figure 10 shows the reduction rate and the activity of carbon in molten iron at various temperature. The reduction rate increases with increasing temperature and decreasing the carbon activity. The reduction rate is nearly constant above 0.5 of activity.

\section{Reduction Temperature}

Figure 11 shows the reduction rate and the temperature. The reduction rate increases with increasing the temperature, except for that the reduction rate at $1420^{\circ} \mathrm{C}$ differs very slightly from that at $1470^{\circ} \mathrm{C}$.

\section{Amount of Molten Iron Oxide}

Figure 12 shows the reduction rate by the carbon in molten iron in alumina crucibles on whose bottom graphite blocks were adhered and the amount of molten iron oxide. The reduction rate increases with increasing the amount of molten iron oxide.

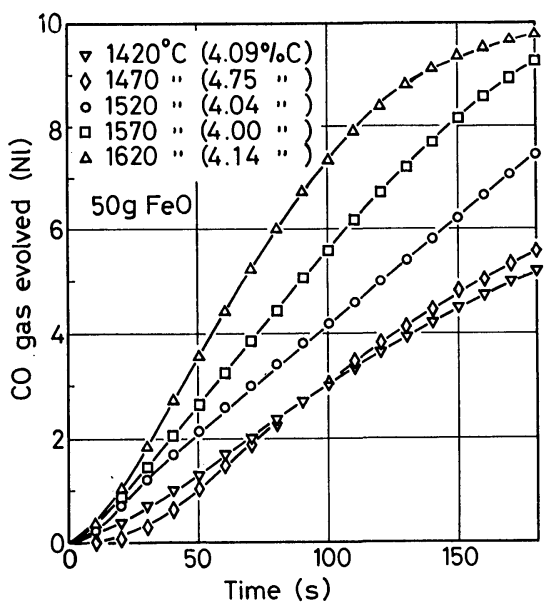

Fig. 9. Amount of $\mathrm{CO}$ gas evolution and the time during the reduction by the carbon in molten iron.

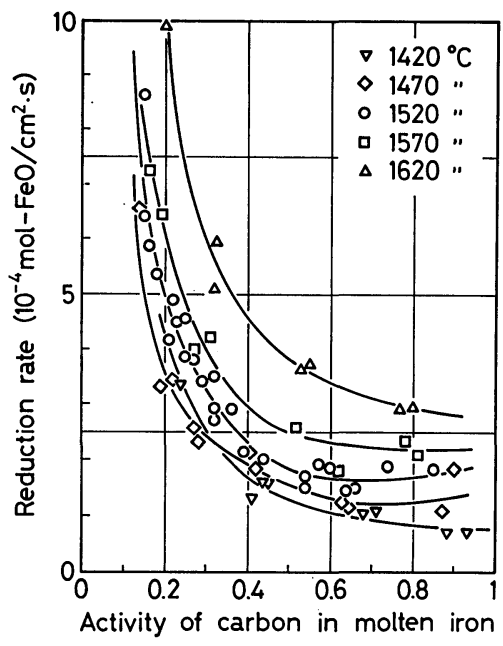

Fig. 10. Reduction rates and the activity of carbon in molten iron. 


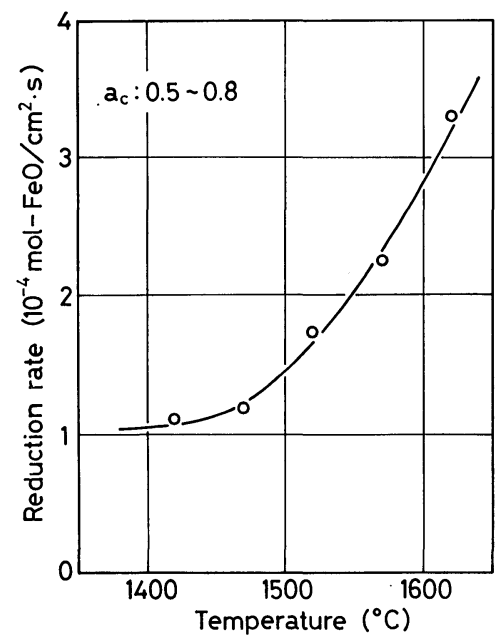

Fig. 11. Reduction rates by the carbon in molten iron and the temperature.

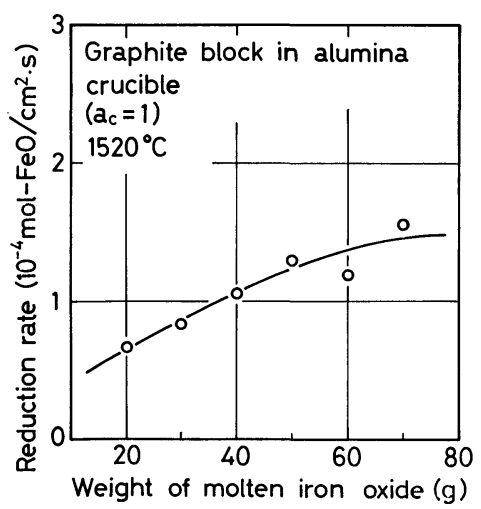

Fig. 12. Reduction rates by the carbon in molten iron and the weight of molten iron oxide.

\section{Discussion}

The area of bottom end of the carbon rod of $5 \mathrm{~mm}$ in diameter is below $5 \%$ of that of side wall of carbon rod when the immersion depth is above $25 \mathrm{~mm}$. Moreover, the area of the reaction interface is the same as that of side wall when the bottom end is a hemisphere. Therefore, the area of bottom end of carbon rod after experiment can be neglected when the immersion depth is about $40 \mathrm{~mm}$. The result in Fig. 5 can be explained from that the area of bottom end affected below $20 \mathrm{~mm}$ of the immersion depth.

The high reduction rate and the hollows on carbon rod with steel crucibles at $1390^{\circ} \mathrm{C}$ and alumina ones at $1429^{\circ} \mathrm{C}$ in Fig. 6 can be explained from that the carbon in molten metal iron which adhered on the rod reacted with molten iron oxide, because the reduction rate by the carbon in molten iron is much higher than that by solid carbon.

Figure 13 shows Arrhenius plot of data in Fig. 6 and Fig. 11. Except for data with steel crucibles at $1390^{\circ} \mathrm{C}$ and alumina ones at $1420^{\circ} \mathrm{C}$, the data points are approximately on straight lines. The activation energies calculated from the slope of these lines are $44 \mathrm{kcal} / \mathrm{mol}$ for the reduction by the carbon in molten iron, 75 and $31 \mathrm{kcal} / \mathrm{mol}$ for the reduction by the

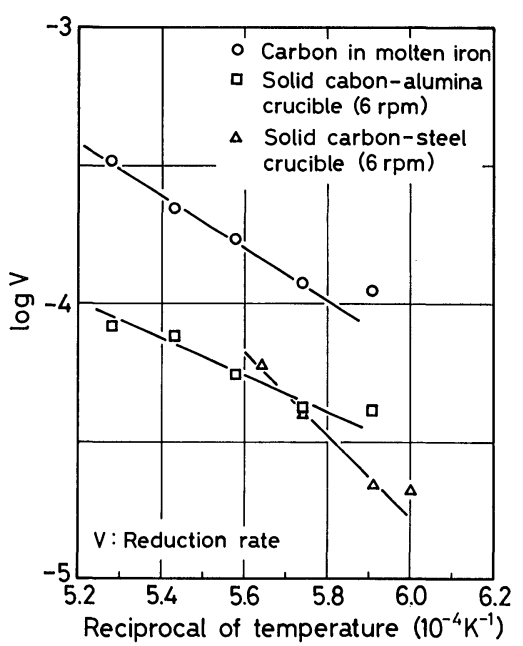

Fig. 13. Arrhenius plot of data in Figs. 6 and 11 .

solid carbon with steel and alumina crucibles, respectively. As shown in Tables 2 and 3, the activation energy for the reduction by the carbon in molten iron is nearly the same as those in reports, but those for the reduction by the solid carbon with steel and alumina crucibles are higher and slightly lower than those in reports. The activation energy of oxygen diffusion in molten slag of $40 \% \mathrm{CaO}-40 \% \mathrm{SiO}_{2}-20 \% \mathrm{Al}_{2} \mathrm{O}_{3}$ is $60 \sim$ $85 \mathrm{kcal} / \mathrm{mol},{ }^{25)}$ and the activation energy obtained with steel crucibles agrees with this value. There is, however, no datum on oxygen diffusion in molten FeO. The activation energy seems to decrease with addition of $\mathrm{CaO}, \mathrm{SiO}_{2}$ and $\mathrm{Al}_{2} \mathrm{O}_{3}$.

The reason why the reduction rate shows the maximum at about $2.5 \% \mathrm{Al}_{2} \mathrm{O}_{3}$, as shown in Fig. 7, can be explained from the viscosity and the concentration of molten iron oxide. The viscosity should be lowest at $6 \% \mathrm{Al}_{2} \mathrm{O}_{3}$ because of an eutectic composition. ${ }^{26)}$ Because the reduction rate increases with decreasing the viscosity and with increasing the concentration of iron oxide, it is considered that the maximum is between $0 \%$ and $6 \% \mathrm{Al}_{2} \mathrm{O}_{3}$.

The reason why the reduction rate shows the maximum with carbon rod of $5 \mathrm{~mm}$ in diameter, as shown in Fig. 8, might be that the GO gas bubbles can form and float away most easily, but the detail mechanism is unknown. The reduction rate increased with increasing the rotation speed of carbon rod with alumina crucibles while it is not affected with steel ones. This can be explained from that the diffusion layer at the reaction interface is decreased by the rotation.

In the reduction of molten iron oxide by the carbon in molten iron, the gas phase is formed between liquids, and reactions expressed by Eqs. (2) and (3) take place simultaneously. ${ }^{15)}$ The reason why the reduction rate increases with increasing the amount of molten iron oxide, as shown in Fig. 12, can be explained from that the reaction expressed by Eq. (2) takes place during floating of $\mathrm{CO}$ gas in the molten iron oxide. Moreover, when the amount of molten iron oxide was little, the surface of molten iron could be seen often from the view-window, and therefore, it is considered that the area of reaction interface decreased. 
Table 2. Researches on the reduction rate of molten iron oxide by the solid carbon.

\begin{tabular}{|c|c|c|c|c|c|c|}
\hline $\begin{array}{l}\text { Author } \\
\text { (Year) }\end{array}$ & Reductant & Iron oxide & $\begin{array}{l}\text { Temper- } \\
\text { ature } \\
\left({ }^{\circ} \mathrm{C}\right)\end{array}$ & $\begin{array}{l}\text { Area } \\
\text { estimated } \\
\left(\mathrm{cm}^{2}\right)\end{array}$ & $\begin{array}{l}\text { Reduction } \\
\text { rate } \\
\left(10^{-4} \mathrm{~mol}^{-}\right. \\
\left.\mathrm{FeO} / \mathrm{cm}^{2} \cdot \mathrm{s}\right)\end{array}$ & $\begin{array}{c}\text { Activation } \\
\text { energy } \\
\text { (kcal/mol) }\end{array}$ \\
\hline $\begin{array}{l}\text { Kondakov et al. }{ }^{17)} \\
\quad(1960)\end{array}$ & $\begin{array}{l}\text { Graphite } \\
\text { crucible }\end{array}$ & $\mathrm{FeO} 0.3 \mathrm{~g}$ & $\begin{array}{l}1450 \\
1600\end{array}$ & unknown & $\begin{array}{l}4.81 \\
5.53\end{array}$ & 38 \\
\hline $\begin{array}{l}\text { Ruidjonkov et al. }{ }^{16)} \\
\quad(1960)\end{array}$ & $\begin{array}{l}\text { Graphite } \\
\text { crucible }\end{array}$ & $\mathrm{FeO} 0.3 \mathrm{~g}$ & 1450 & unknown & 3.94 & - \\
\hline $\begin{array}{l}\text { Sugata et al. }{ }^{21)} \\
\quad(1972)\end{array}$ & Graphite rod & $\begin{array}{r}\text { Molten } \mathrm{SiO}_{2}-69 \% \mathrm{FeO} \\
-78 \% \mathrm{FeO} \\
-69 \% \mathrm{FeO} \\
\end{array}$ & $\begin{array}{l}1350 \\
1400 \\
1450\end{array}$ & $\begin{array}{l}31.4 \\
28.6 \\
31.4\end{array}$ & $\begin{array}{l}0.09 \\
0.19 \\
0.23\end{array}$ & 40 \\
\hline $\begin{array}{l}\text { Takahashi et al. }{ }^{18)} \\
\quad(1975)\end{array}$ & $\begin{array}{l}\text { Graphite } \\
\text { crucible }\end{array}$ & $\mathrm{Fe}_{2} \mathrm{O}_{3}$ ore $12 \mathrm{~g}$ & $\begin{array}{l}1410 \\
1570\end{array}$ & $\begin{array}{l}\sim 30 \\
\sim 30\end{array}$ & $\begin{array}{l}0.20 \\
0.79\end{array}$ & 56 \\
\hline $\begin{array}{l}\text { Sasaki et al. }{ }^{19)} \\
\quad(1978)\end{array}$ & $\begin{array}{l}\text { Graphite } \\
\text { crucible }\end{array}$ & 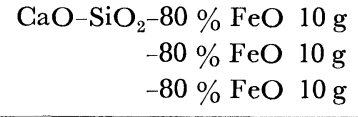 & $\begin{array}{l}1400 \\
1500 \\
1600\end{array}$ & $\begin{array}{l}\sim 25 \\
\sim 25 \\
\sim 25\end{array}$ & $\begin{array}{l}0.50 \\
0.72 \\
0.99\end{array}$ & $20 \sim 30$ \\
\hline $\begin{array}{l}\text { Tsukihashi et al. }{ }^{20)} \\
\text { (1982) }\end{array}$ & $\begin{array}{l}\text { Graphite } \\
\text { crucible }\end{array}$ & $\mathrm{Fe}_{2} \mathrm{O}_{3}$ ore $10 \mathrm{~g}$ & $\begin{array}{l}1400 \\
1500\end{array}$ & $\begin{array}{l}\sim 9 \\
\sim 9\end{array}$ & $\begin{array}{l}0.26 \\
0.42\end{array}$ & - \\
\hline \multirow[t]{2}{*}{ Present work } & \multirow[t]{2}{*}{$\begin{array}{l}\text { Graphite rod } \\
6 \mathrm{rpm}\end{array}$} & $\begin{array}{l}\text { Molten } \mathrm{FeO} \text { in alumina } \\
\text { crucible }\end{array}$ & $\begin{array}{l}1470 \\
1520 \\
1620\end{array}$ & $\begin{array}{l}\sim 7 \\
\sim 7 \\
\sim 7\end{array}$ & $\begin{array}{l}0.42 \\
0.54 \\
0.82\end{array}$ & 31 \\
\hline & & $\begin{array}{l}\text { Molten } \mathrm{FeO} \text { in steel } \\
\text { crucible }\end{array}$ & $\begin{array}{l}1420 \\
1470 \\
1500\end{array}$ & $\begin{array}{l}\sim 7 \\
\sim 7 \\
\sim 7\end{array}$ & $\begin{array}{l}0.21 \\
0.41 \\
0.61\end{array}$ & 75 \\
\hline
\end{tabular}

Table 3. Researches on the reduction rate of molten iron oxide by the carbon in molten iron.

\begin{tabular}{|c|c|c|c|c|c|c|}
\hline Author & Reductant & Iron oxide & $\begin{array}{l}\text { Temperature } \\
\left({ }^{\circ} \mathrm{C}\right)\end{array}$ & $\begin{array}{c}\text { Area } \\
\text { estimated } \\
\left(\mathrm{cm}^{2}\right)\end{array}$ & $\begin{array}{c}\text { Reduction } \\
\text { rate } \\
\left(10^{-4} \mathrm{~mol}-\right. \\
\left.\mathrm{FeO} / \mathrm{cm}^{2} \cdot \mathrm{s}\right)\end{array}$ & $\begin{array}{c}\text { Activation } \\
\text { energy } \\
\text { (kcal/mol) }\end{array}$ \\
\hline \multirow{5}{*}{$\begin{array}{c}\text { Dancy }^{22)} \\
(1951)\end{array}$} & \multirow[t]{5}{*}{$4.3 \mathrm{wt} \% \mathrm{C} 50 \mathrm{~g}$} & \multirow[t]{3}{*}{$\mathrm{FeO} 0.5 \mathrm{~g}$} & 1430 & $\sim 1$ & 31.73 & \multirow[t]{3}{*}{43} \\
\hline & & & 1500 & $\sim 1$ & 34.80 & \\
\hline & & & 1610 & $\sim 1$ & 86.99 & \\
\hline & & \multirow[t]{2}{*}{$\mathrm{Fe}_{3} \mathrm{O}_{4} 0.5 \mathrm{~g}$} & 1580 & $\sim 1$ & 34.80 & \multirow[t]{2}{*}{37} \\
\hline & & & 1650 & $\sim 1$ & 48.99 & \\
\hline \multirow{2}{*}{$\begin{array}{l}\operatorname{Mac}^{\operatorname{Man} \mathrm{Re}^{23)}} \\
\quad(1965)\end{array}$} & \multirow{2}{*}{ Sat. C $600 \mathrm{~g}$} & \multirow{2}{*}{$\mathrm{Fe}_{2} \mathrm{O}_{3} 3 \mathrm{~g}$} & 1335 & $\sim 3$ & 4.03 & \multirow{2}{*}{$27 \sim 44$} \\
\hline & & & 1450 & $\sim 3$ & 8.80 & \\
\hline \multirow{2}{*}{$\begin{array}{l}\text { Lloyd et al.24) } \\
\quad(1975)\end{array}$} & \multirow{2}{*}{$4.15 \mathrm{wt} \% \mathrm{C} 200 \mathrm{~g}$} & \multirow{2}{*}{$\mathrm{Fe}_{2} \mathrm{O}_{3} 0.7 \mathrm{~g}$} & 1400 & 0.54 & 7.94 & \multirow[t]{2}{*}{56} \\
\hline & & & 1600 & 0.44 & 50.12 & \\
\hline \multirow{9}{*}{$\begin{array}{l}\text { Sato }^{7)} \\
\quad(1981)\end{array}$} & \multirow[t]{9}{*}{ Sat. C $1500 \mathrm{~g}$} & \multirow[t]{3}{*}{$\mathrm{FeO} 20 \mathrm{~g}$} & 1420 & $\sim 7.7$ & 3.55 & \multirow[t]{3}{*}{42} \\
\hline & & & 1520 & $\sim 7.7$ & 5.18 & \\
\hline & & & 1620 & $\sim 7.7$ & 8.58 & \\
\hline & & \multirow[t]{3}{*}{$\mathrm{Fe}_{3} \mathrm{O}_{4} 30 \mathrm{~g}$} & 1420 & $\sim 8.6$ & 5.41 & \multirow[t]{3}{*}{23} \\
\hline & & & 1520 & $\sim 8.6$ & 8.35 & \\
\hline & & & 1620 & $\sim 8.6$ & 10.48 & \\
\hline & & \multirow[t]{3}{*}{$\mathrm{Fe}_{2} \mathrm{O}_{3} 15 \mathrm{~g}$} & 1420 & $\sim 7.3$ & 5.82 & \multirow[t]{3}{*}{23} \\
\hline & & & 1520 & $\sim 7.3$ & 8.13 & \\
\hline & & & 1620 & $\sim 7.3$ & 11.68 & \\
\hline $\begin{array}{l}\text { Tsukihashi et al.20) } \\
\quad(1982)\end{array}$ & $3 \mathrm{wt} \% \mathrm{C} 100 \mathrm{~g}$ & $\mathrm{Fe}_{2} \mathrm{O}_{3}$ ore $10 \mathrm{~g}$ & 1500 & $\sim 6$ & 2.32 & - \\
\hline \multirow[t]{3}{*}{ Present work } & \multirow[t]{3}{*}{$3 \sim 4.5 \mathrm{wt} \% \mathrm{C} 1500 \mathrm{~g}$} & \multirow[t]{3}{*}{ Molten FeO (50 g) } & 1470 & 19.6 & 1.19 & \multirow[t]{3}{*}{44} \\
\hline & & & 1520 & 19.6 & 1.73 & \\
\hline & & & 1620 & 19.6 & 3.30 & \\
\hline
\end{tabular}


Table 2 and Table 3 show the reduction rates of molten iron oxide by the solid carbon and the carbon in molten iron, respectively, obtained in the present experiment and reported up to the present. The reduction of molten iron oxide by carbon takes with the bubble formation, and therefore, the estimation of the area of reaction interface is very difficult. As seen in Table 2, the reduction rates by the solid carbon are nearly the same except for those obtained with small amount of iron oxide dropped into graphite crucibles. As seen in Table 3, the reduction rates obtained with small amount of iron oxide dropped onto the surface of molten iron are fairly high. Moreover, the reduction rates of molten iron oxide by the carbon in molten iron obtained by the present experiment are lower than those of solid iron oxide by the carbon in molten iron, as reported by Lloyd et al. ${ }^{24)}$

The reduction rates of molten iron oxide by reducing gases, such as $\mathrm{CO}, \mathrm{H}_{2}$, are 0.61 and $1.11 \times$ $10^{-4} \mathrm{~mol}-\mathrm{FeO} / \mathrm{cm}^{2} \cdot \mathrm{s} \cdot \mathrm{atm}$ at $1450^{\circ} \mathrm{G}$ by Ban-ya et $a l .{ }^{27,28)}$ The reduction rates of molten iron oxide by reducing gases are higher than those of solid iron oxide by reducing gases, but lower than those of molten iron oxide by the carbon in molten iron. Because the dissolution rate of stationary carbon rod into molten iron is fairly high, $4 \sim 11 \times 10^{-4} \mathrm{~mol}-\mathrm{C} / \mathrm{cm}^{2}$. $\mathrm{s}{ }^{29)}$ the high productivity can be realized by using the carbon in molten iron in smelting reduction processes. Up to the present, the reduction rate of solid iron oxide by the carbon in molten iron is the highest, and therefore, it should be desirable to utilize this reaction to the utmost limit.

\section{Conclusions}

The reduction rates of molten iron oxide by the solid carbon and the carbon in molten iron were calculated from the amount of $\mathrm{CO}$ gas evolution measured. The following results were obtained:

(1) The reduction rates of molten iron oxide by the solid carbon were $0.21 \sim 0.82 \times 10^{-4} \mathrm{~mol}-\mathrm{FeO} /$ $\mathrm{cm}^{2} \cdot \mathrm{s}$ at $1420 \sim 1620^{\circ} \mathrm{C}$, and the activation energy of the reaction were 75 and $31 \mathrm{kcal} / \mathrm{mol}$ with steel and alumina crucibles, respectively. The reduction rates with steel crucibles at $1390^{\circ} \mathrm{C}$ and with alumina ones at $1420^{\circ} \mathrm{G}$ were rather higher than those estimated from the other data of the present experiment.

(2) The reduction rates of molten iron oxide by the carbon in molten iron were $1.1 \sim 3.3 \times 10^{-4}$ mol$\mathrm{FeO} / \mathrm{cm}^{2} \cdot \mathrm{s}$ at $1420 \sim 1620^{\circ} \mathrm{C}$, and the activation energy of the reaction was $44 \mathrm{kcal} / \mathrm{mol}$. The reduction rates increased with increasing the amount of molten iron oxide, and the values mentioned above were obtained with $\mathrm{FeO}$ of $50 \mathrm{~g}$ which corresponded to the depth of $6 \sim 7 \mathrm{~mm}$ of molten iron oxide.

(3) The reduction rates of solid iron oxide by the carbon in molten iron are concluded to be the highest among reduction rates of solid or molten iron oxide by the solid carbon, the carbon in molten iron or reducing gases, such as $\mathrm{CO}, \mathrm{H}_{2}$, based on the experi- mental results up to the present.

\section{REFERENGES}

1) T. Soma: Bull. Jpn. Inst. Met., 21 (1982), 620.

2) M. Nakamura and N. Tokumitsu: Tetsu-to-Hagané, 67 (1981), 480.

3) A. Sato, N. Nakagawa, S. Yoshimatsu, A. Fukuzawa, T. Ozaki, K. Kasahara, Y. Fukuzawa and T. Mitsui: Trans. Iron Steel Inst. Jpn., 19 (1979), 112.

4) A. Sato, K. Kasahara, R. Nakagawa, S. Yoshimatsu, A. Fukuzawa, T. Ozaki, Y. Iwai, Y. Fukuzawa and T. Mitsui: Trans. Iron Steel Inst. Jpn., 19 (1979), 490.

5) A. Sato, R. Nakagawa, S. Yoshimatsu, A. Fukuzawa and T. Ozaki: Trans. Iron Steel Inst. Jpn., 20 (1980), 33.

6) A. Sato, R. Nakagawa, S. Yoshimatsu, A. Fukuzawa and T. Ozaki: Trans. Iron Steel Inst. Jpn., 21 (1981), 66.

7) A. Sato, R. Nakagawa, S. Yoshimatsu, A. Fukuzawa and T. Ozaki: Trans. Iron Steel Inst. Jpn., 21 (1981), 879.

8) A. Sato, G. Aragane, F. Hirose, R. Nakagawa and S. Yoshimatsu: Trans. Iron Steel Inst. Jpn., 24 (1984), 808.

9) A. Sato, G. Aragane, N. Sakuma, R. Nakagawa and S. Yoshimatsu: Trans. National Research Inst. Metals, 27 (1985), 174.

10) K. Kamiya, K. Kasahara, F. Matsumoto, M. Tanaka and S. Yoshimatsu: Tetsu-to-Hagané, 68 (1982), S73.

11) K. Kasahara, K. Kamiya, F. Matsumoto, M. Tanaka and S. Yoshimatsu: Tetsu-to-Hagané, 68 (1982), S842.

12) A. Sato, G. Aragane, A. Kasahara, K. Kamihira and S. Yoshimatsu: Tetsu-to-Hagané, 69 (1983), S24; Trans. Iron Steel Inst. Jpn., 23 (1983), B316.

13) K. Kamiya, K. Kasahara, F. Matsumoto and S. Yoshimatsu: Tetsu-to-Hagané, 70 (1984), S834.

14) S. Shimoo and H. Kimura: J. Jpn. Inst. Met., 42 (1978), 523.

15) Iron and Steel Handbook, I: Foundamental Theory of Iron and Steel, ed. by Iron Steel Inst. Japan., Maruzen, Tokyo, (1981), 102.

16) D. I. Ruidjonkov, D. M. Golenko and L. M. Cheliadinov: Izv. VUZ Chern. Metall., (1960), No. 4, 19.

17) V. V. Kondakov, D. I. Ruidjonkov and D. M. Golenho: Izv. VUZ Chern. Metall., (1960), No. 4, 23.

18) K. Takahashi, M. Amatatsu and T. Soma: Tetsu-to-Hagané, 61 (1975), 2525.

19) Y. Sasaki and T. Soma: Tetsu-to-Hagané, 64 (1978), 376.

20) F. Tsukihashi, M. Amatatsu and T. Soma: Tetsu-to-Hagané, 68 (1982), 1880.

21) M. Sugata, T. Sugiyama and S. Kondo: Tetsu-to-Hagané, 58 (1972), 1363.

22) T. E. Dancy: J. Iron Steel Inst., 189 (1951), 17.

23) D. R. Mac Rae: J. Met., 17 (1965), 1391.

24) G. W. Lloyd, D. R. Young and L. A. Baker: Ironmaking Steelmaking, 2 (1975), 49.

25) Iron and Steel Handbook, I: Foundamental Theory of Iron and Steel, ed. by Iron Steel Inst. Japan., Maruzen, Tokyo, (1981), 44.

26) E. L. Levin and H. F. McMurdie: Phase Diagrams for Ceramsits, 1975 Supplement, Am. Ceram. Soc. Inc., Columbus, (1975).

27) T. Nagasaka, Y. Iguchi and S. Ban-ya: Tetsu-to-Hagané, 71 (1985), 204.

28) S. Ban-ya, Y. Iguchi and T. Nagasaka: Tetsu-to-Hagané, 70 (1984), 1689.

29) M. Kosaka and S. Minowa: Tetsu-to-Hagané, 53 (1967), 1467. 